\title{
CRIME PREVENTION AND COMMUNITY SAFETY: A CONCEPTUAL OVERVIEW
}

\author{
Michel Vallée
}

\begin{abstract}
The author explores some of the factors that have influenced the public debate in Canada over issues of crime and victimization, particularly with reference to children and youth as both perpetrators and victims. Focusing specifically on various approaches to crime prevention, he discusses some of the key elements of a comprehensive crime prevention strategy and argues that for such a strategy to be meaningful and effective, it should be a community-based social development approach
\end{abstract}

This article, which serves as an introduction to Volume 1, Number 1 and Number 2 of the International Journal of Child, Youth and Family Studies explores some of the factors that have influenced public discourse in Canada surrounding crime and victimization, focusing specifically on an assessment of various crime prevention strategies and approaches. Building on this analysis, some of the key elements of a comprehensive crime prevention strategy are discussed. Finally, I consider why a comprehensive crime prevention strategy based on a social development approach has the greatest potential to affect crime and victimization.

As noted in the preface, the papers in this collection present a multidisciplinary analysis of crime prevention with a particular emphasis on the safety, health, and wellbeing of children and youth. This emphasis was the focus of the policy forum upon which this volume is based, and was selected through a series of discussions and negotiations with senior federal government officials from several departments who participated in the event. While these policy-makers shared a general interest in crime prevention programs and strategies, a broad consensus emerged during negotiations with these federal representatives that the focus of our discussion on crime prevention should be on the experiences of children and youth.

Both the research literature and public opinion polls in Canada reflect the importance of addressing the experiences of children and youth as both victims and perpetrators of crime. For example, an Earnscliffe survey (2000) reported results that are typical of public opinion in Canada regarding youth involvement in crime. This survey showed that crime, and youth crime in particular, is near the top of the public agenda. An EKOS survey (2004) confirms these findings, suggesting a continued perception by Canadians that crime is increasing and that crime involving youth is increasing more dramatically than other crimes. In fact, three-quarters of Canadians perceive that violent crimes and property crimes committed by youth, as well as school-based violence, are increasing. 
While youth crime and victimization have garnered considerable public concern, children and youth have also become the focus of much crime prevention activity in Canada. A study of crime prevention practices in 29 Canadian communities by Jamieson, Beals, Lalonde \& Associates (2000) revealed that, “In all 29 communities, youth and children were identified as the major program beneficiaries” (p. 5). Indeed, many of the programs identified during this study involved the police or schools in educational, recreational, or mentoring activities aimed at children and youth. While most communities had traditional situational programs and activities, the majority of the activities identified were "Crime Prevention through Social Development" (CPSD) in orientation. In most communities, the police were the main group participating in both situational crime prevention and CPSD.

Similar results were reported by Jamieson and Hart (2003) in their review of promising crime prevention practices in Canada. In their compendium, fully 30 of the 39 programs identified focused on activities aimed at children and youth. Another example of the importance of children and youth in the area of crime prevention is a report by Arcand and Cullen (2004). This study examined the role of the police in Crime Prevention through Social Development. Of the 54 programs identified in this report, $68.5 \%$ had an educational focus while $26 \%$ involved recreational activities. Most of these programs were designed for children and youth.

The focus on children and youth in the area of crime prevention reflects a wide range of societal concerns and beliefs about crime and victimization. For example, Canadians generally favour prevention over punishment for youth. This is illustrated in the EKOS survey report (2004):

For the majority of Canadians, providing young people at risk of offending with opportunities (e.g., training, rehabilitation or recreational programs) is by far the preferred approach to crime prevention. Alternatively, attempting to deter youth from committing crimes through increased law enforcement methods such as "tougher sentences" is favoured by about one in four. The perception that opportunities are the best way to prevent youth crime has increased from 68 per cent in 2000 to 73 per cent in 2003. (p. 24)

Identifying children and youth as both "victims" and "villains" reflects many of the dominant cultural stereotypes surrounding the concept of "childhood". On the one hand, these stereotypes portray children as innocent and passive victims who need guidance and nurturing. On the other hand, some children and youth are identified as potentially dangerous and criminal actors in need of punishment and control. The "victim" imagery is based on the notion that children need guidance and protection from the dangers of adult life. This view defines children and youth as not fully developed, offering the potential of successful socialization or even rehabilitation. Many programs aimed at children and youth are based on just such a premise, that is, children and youth can be educated and made aware of potential dangers (drugs, crime, unsafe sexual activities, 
etc.). Educational, recreational, and mentoring programs (to name a few) can be designed to encourage the development of pro-social behaviour patterns in the young.

At the same time, enforcement efforts aimed at youth crime, including violence, drugs, and gang activity, respond to people's fear of crime. Indeed, many offenders fall into the 14- to 24-year-old age range confirming societal concerns regarding youth crime. Attitudes toward prevention and rehabilitation, however, also reflect dominant stereotypes. Given their potential for future growth, general attitudes toward youth that run afoul of the law perceive good candidates for reform and rehabilitation efforts in comparison to adult offenders who are thought to be more set in their ways and therefore less susceptible to change.

In the sections that follow, issues related to crime and its prevention are discussed in a general way, especially with respect to identifying the major types of crime prevention. The relevance of this discussion for the safety, health, and well-being of children and youth is implicit; however, specific reference will be made to the implications of the discussion for children and youth where appropriate.

\section{Crime and its Prevention in Canada}

Over the past decade neo-liberal thinking has dominated political discourse in most western nations including discussions of law and order. This has stemmed from the influence in the early 1980s of the Reagan Administration in the United States and the Thatcher Government in Britain. In the area of crime and corrections, this has meant an emphasis on "get tough" measures, harsher punishments, and higher incarceration rates. However, despite this focus on a so-called "law and order" approach, there has been a growing recognition by researchers, policy-makers, and service providers alike, that many of the existing traditional responses to crime and victimization are ineffective. For example, there are very real limits to what the criminal justice system can achieve in terms of preventing crime, deterring criminals, or making our homes and communities safer. While the most concrete outcome of Canada's current approach to crime is an incarceration rate that is among the highest in the world, crime and victimization rates continue to remain high. The limits of the judicial process as a crime prevention tool are also evident when we consider that the criminal courts and the sanctions they provide do not deal with the root causes of crime. Rather, they deal with the situational events surrounding a crime and the offender. A similar argument can be made with respect to the limited effectiveness of correctional treatment and rehabilitation programs. As Gendreau and Ross (1987) note, it is unfortunate that the discussion of treatment effectiveness has become almost dogmatic and influenced by the prevailing political climate. While some correctional programs do have positive preventive effects on some offenders, they cannot be considered as an effective mechanism for preventing crime and victimization in any comprehensive manner.

Interestingly, public perceptions about crime and victimization have not changed much over the past several decades in Canada. The Canadian public continues to see crime as being stable or increasing and, as noted above, believes that youth are 
responsible. A review of studies and polls describing the views of Canadians confirms this conclusion. For example, an EKOS survey (2004) indicates that a majority of Canadians continue to believe that crime is either at the same level or increasing, but not by as much as in a previous survey (EKOS, 2001). As well, the public is concerned about their children's safety in schools. On the other hand, Canadians feel safe from property and violent crimes within their own neighbourhoods.

Importantly, however, while the Canadian public sees crime as being an important issue, they are also aware of the significance of key risk factors related to crime, such as difficulties within families and schools, problems related to drugs and alcohol, and poverty. In fact, in recent surveys, the public has expressed its support for crime prevention initiatives and has endorsed directing greater attention and resources to the "causes" of crime. For example, the EKOS (2004) report notes that by a margin of two to one the public prefers crime prevention to punishment as a primary goal of the criminal justice system. Moreover, three in four Canadians would rather see an approach to youth crime that offers opportunities to get involved in positive activities, such as training and drug rehabilitation, rather than imposing tougher sentences. More specifically, the report states:

Respondents were presented with a hypothetical situation where they were forced to choose between a series of randomly paired choices on how best to reduce crime. The results show that, almost two out of three times, the expansion of literacy and training programs for youth was selected when paired against other options. Further evidence of the public's preference for proactive solutions to address crime can be found in the support for increasing early childhood intervention, parenting programs, youth recreational activities, and public education programs, which were selected more than half of the time as the most effective form of crime reduction.

(EKOS, 2004, p. 36)

In order to identify some key elements of an effective crime prevention strategy, it is important to begin by considering what we mean by “crime prevention”. Harvey, Grimshaw, and Pease (1989) suggest that there are effectively no real boundaries to crime prevention work, and that proponents and practitioners subsume widely divergent practices under the headings of "crime prevention" and "community safety". Crawford (1998) points out that genuine prevention is inherently difficult to assess. It involves securing a "non-event". Hastings (1995) suggests that there are three specific tasks in developing a blueprint for prevention. These are: (a) defining the crime problem from the perspective of society, victims, and community; (b) deciding on the appropriate level of intervention, i.e., primary prevention or problem focused, secondary prevention focused on a specific situation or individuals, or tertiary prevention focusing on individuals who have already been involved in an offence; and, (c) deciding on the appropriate point of intervention, i.e., the motivation of the offender, the vulnerability of the victim, and the situation or the opportunity that could give rise to the criminal act. 
There have been many efforts to classify crime prevention approaches. For example, Lejins (1967) talks about differentiating between the techniques employed in crime prevention activities, e.g., punitive prevention or deterrence, corrective prevention or the elimination of criminogenic social conditions, and mechanical prevention or measures to reduce criminal opportunities. Further to this, Crawford (1998) writes, “....in trying to define crime prevention's conceptual boundaries, we recognize that crime prevention is somewhere between the narrow craft of 'policing' and the elephantine and somewhat amorphous processes of social control” (p. 8). Lab (1997) states that crime prevention entails any action designed to reduce the actual level of crime and/or perceived fear of crime. Hastings (1995), however, indicates that prevention should mean a great deal more than better law enforcement.

Definitions of crime prevention, its boundaries, and appropriate conceptualizations remain the subject of intense debate and considerable academic interest. Seeking agreement on a workable definition of crime prevention is not an easy task, nor is trying to determine at what point to intervene and at what level. These are difficult choices to make. Crawford (1998) states that these choices, "...embody assumptions about causes of crime, the nature of social relations and principles of justice, as well as, at the same time they connect with, and are promoted by, political strategies and ideological perspectives” (p. 3).

The nature of prevention strategies can range on a continuum that includes tertiary intervention (e.g., correctional treatment measures) at one end, secondary prevention (e.g., situational crime prevention) in the middle, and primary prevention (e.g., social development) at the other end. Prevention can be multi-dimensional by focusing on all three levels of intervention in an integrated manner. At the same time, crime prevention can be comprehensive and include the health care, child welfare, education, and criminal justice systems, as well as retaining a significant role for the local community. This latter approach emphasizes the need to take a broader look at the root causes of crime and develop a more comprehensive crime prevention strategy.

The House of Commons Standing Committee on Justice and the Solicitor General (SCJSG) provides strong support for a comprehensive approach to crime prevention in their concluding statement:

The Committee accepts that crime will always be with us in one form or another, and will require police, court, and correctional interventions. At the same time, it believes that our collective response to crime must shift to crime prevention efforts that reduce opportunities for crime and focus increasingly on at-risk young people and on the underlying social and economic factors associated with crime and criminality. This comprehensive approach involves partnerships between governments, criminal justice organizations, and community agencies and groups. As well, it situates the crime problem in a community context and sees its solution as a social question. (Government of Canada, 1993, p. 2) 
Do we really know what underlying social and economic factors are associated with crime and criminality? Can we recognize the impact and effects of these factors? Social science research has identified many interrelated factors in the social environment of persistent offenders that contribute to their criminality. A number of witnesses at the 1993 SCJSG hearings emphasized the relationship between the following:

1. Dropping out of school and coming into contact with the juvenile justice system;

2. Illiteracy, school failure, low self-esteem, and crime;

3. Inappropriate disciplinary methods of parents (lack of consistency is the worst) and delinquency;

4. Violent behaviour by young and adult offenders; and

5. Witnessing and/or experiencing physical or sexual abuse as children.

It is clear that there is no single "cause" of crime. Rather, crime is the outcome of the interactions of a constellation of factors that include: poverty, physical and sexual abuse, illiteracy, alcohol abuse, drug abuse, lack of job opportunities for youth, negative peer influence, physiological defects (e.g., FAS/FAE), biological defects (chromosome imbalance, tumours, etc.), low self-esteem, inadequate housing, school failures, unemployment, inequality, and dysfunctional families.

Crawford (1998) also identifies a number of variables that impact crime. In addition to gender (most crimes are committed by men), he discusses the impact of the following: (a) individual personality and behavioural factors, such as hyperactive behaviour in early childhood, impulsiveness, and restlessness; (b) family influences, such as social class, family size, family poverty, lone-parenting, inadequate parenting, physical and sexual abuse, parental conflict and separation; (c) living conditions, such as poor housing and unstable living conditions; (d) disintegration of social supports; (e) school influences, such as poor schooling, bullying, poor educational achievements, truancy, and exclusion from school; (f) peer group pressure, delinquency or having friends who are involved in delinquent activities; and, (g) employment issues, such as a lack of training and unemployment.

\section{Crime Prevention Strategies}

The discussion above demonstrates that many factors and variables have been associated with crime. It also shows that there are numerous strategies or approaches to crime prevention and many ways to categorize and describe them. In the following discussion, I consider the strengths and weaknesses of four key crime prevention approaches:

1. Community Crime Prevention

2. Situational Crime Prevention

3. Developmental Crime Prevention

4. Crime Prevention through Social Development 


\section{Community Crime Prevention}

Community crime prevention is sometimes referred to as neighbourhood crime prevention because, for the most part, these programs tend to focus on local, identifiable entities such as neighbourhoods. It is called "community crime prevention" even when implemented on a city-wide basis. Community crime prevention seeks to directly influence intervening constructs such as social cohesion, community atmosphere, and surveillance. Additionally, these programs try to affect community cohesion, crime levels, and the fear of crime. Neighbourhood or Block Watch programs, Block Parents, citizen patrols and general police-community initiatives (such as education programs, social events, anti-drug activities, etc.) are excellent examples of such community crime prevention programs.

Evaluation studies of the effectiveness of community crime prevention show mixed results. Early research found that familiarity with neighbours and the community increases with participation in block parties and social events. However, later studies paint a bleaker picture. For example, in a study of two Neighbourhood Watch programs in London, England, Bennett (1990) finds that social cohesion increased in one area and decreased in the other. In addition, building on an analysis of four organized neighbourhoods in Chicago, Rosenbaum (1986) reports no change in the social cohesion in three areas and actually found decreased social cohesion in the fourth.

In general, the literature regarding Neighbourhood Watch programs is mixed. For example, Lab (1997) reports that the literature on citizen patrols suggests that they can be effective in reducing both crime and fear, but that police foot patrols have had mixed results. He points out that the evidence supports the idea of communal action as a successful Neighbourhood Watch means of combating crime and the fear of crime. Gerbner, Cirel, Evans, McGillis, and Whitcomb (1977) also report that official crime records reveal a positive impact of programs. However, some observers have raised questions about the effectiveness of these programs and whether they merely displace crime rather than prevent it. Others have criticized neighbourhood or community crime prevention because these types of programs are aimed primarily at property offences. They have little, if any, impact on interpersonal violence because much of this type of behaviour goes on behind closed doors. Nor do they address other types of crime such as white collar and corporate crime, computer and Internet-based crime, or economic crime.

An example of an early neighbourhood crime prevention strategy was based on Broken Windows Theory (Wilson \& Kelling, 1982, 1989). This theory stresses police and citizen foot patrols and greater community efforts to clean up neighbourhoods. Broken Windows Theory formed the basis of the State of New Jersey's "Safe and Clean Neighborhood Program" in the mid-1970s, as well as efforts in New York City in the 1980s. Wilson (1983) reports on the New Jersey experience and points out that while some success was observed with respect to the "clean-up" of the neighbourhood, there was no evidence that foot patrols had reduced crime rates. 
Neighbourhood or community crime prevention is appealing because it reflects a "common sense" approach to crime. That is, if we are watching out for each other (including our property), we are less likely to be victimized. By extension, having police officers or citizens patrol neighbourhood streets gives the impression that someone is there to protect us. However, this approach to crime prevention has encountered considerable criticism and is limited in its focus. A salient lesson learned from the experience with community crime prevention is that the involvement of community members is a crucial factor in developing an effective crime prevention strategy.

There has been renewed interest in community crime prevention strategies as a result of the recent focus on social capital as a policy and program instrument. Social capital has come to be seen in community crime prevention as a key ingredient in policecitizen neighbourhood interventions. The role of social capital has been highlighted in the work of Sampson and Raudenbush (1999) in Chicago neighbourhoods. Their efforts in promoting interventions related to social capital and based on informal neighbourhood relationships, as a tool to reduce minor street crimes and disorder, appear to have had an impact on reducing violent crimes in these neighbourhoods.

Corrado, Cohen, Irwin, and Davies (2005) present recent research on social capital that suggests that community networks need to be expanded beyond just police links or coordinated programs to include early education intervention programs, health care, and employment schemes. Their discussion regarding the importance of social capital raises a number of questions about the concept and its use. To begin with, a clear definition of this concept is required if policies and programs are to be developed based on social capital. At the moment, such a definition is not available and there is considerable debate over how social capital should be defined and applied. While it is beyond the scope of this article to provide a detailed discussion of these issues, suffice it to say that a working definition of social capital is required which is sufficiently broad to encompass the experiences of neighbourhoods with informal networks, yet narrow enough to differentiate between these informal networks and other social interaction that goes on in neighbourhoods between residents and such professionals as teachers and police officers who work there. Calling all relationships and social networks in a community "social capital" does not allow us to distinguish between various forms of social interaction and their impact on community functioning. Moreover, this discussion brings several other key variables into focus including the definition of community, the meaning of community-based, and who qualifies as a member of a community or neighbourhood. Equally important is a clarification of the role that professionals have in these contexts.

\section{Situational Crime Prevention}

The prioritizing of crime prevention efforts is nowhere more evident than under the umbrella of situational crime prevention strategies. One of its distinctive features is the targeting of a specific problem, place, or person. Canada's National Crime Prevention Centre (2000b) describes situational crime prevention as a "common sense” approach to crime prevention. It is referred to as such because situational crime prevention often 
involves taking simple, common sense steps to reduce or eliminate opportunities for crime. Some examples of this common sense approach include not leaving your car keys in the ignition when you leave your car, locking your doors when you leave home, not leaving packages in your unattended car, and taking other such common sense precautions.

Clarke (1983) suggests that situational crime prevention generally focuses on highly specific forms of crime. It involves the management, design, or manipulation of the immediate environment. It is systemic and permanent, and aims to reduce the opportunities for crime, as well as increasing the risk of engaging in criminal activities for a wide range of offenders. Crawford (1998) simplifies this discussion by suggesting three premises for situational crime prevention: (a) reduce the opportunity of crime; (b) increase the risk of detection; and (c) reduce the rewards of crime.

It is difficult to define situational crime prevention without mentioning its two precursors, i.e., opportunity reduction (Jane Jacobs, 1961) and defensible space (Oscar Newman, 1972). Moreover, the popularization of the concept of Crime Prevention through Environmental Design (CPTED) represents one of the more well-known and well-utilized situational crime prevention strategies. The CPTED approach suggests that the physical environment can be manipulated to influence behaviours that ultimately reduce the incidence and fear of crime. Further, Crowe (2000) suggests that there is a resurgence of interest in CPTED. For example, he refers to recent efforts of the State of Florida, which has gone so far as to pass a law entitled the "Safe Neighborhood Act". This law provides legal authority and funding for the implementation of CPTED strategies.

Lab (1997) writes that situational crime prevention offers an approach that seeks to target specific problems with individualized intervention. These techniques epitomize the idea of secondary prevention. Many of the studies of situational crime prevention, such as those by DesChamps, P. L. Brantingham, and P. J. Brantingham (1991) on transit system fare avoidance in British Columbia, and Ekblom (1992) on preventing post office robberies in London, England, indicate a significant measure of short-term success. Another example is the recent crime reduction effort based on the use of Closed Circuit Television (CCTV). Welsh and Farrington (2004) report on a meta-analysis of what they deem as the highest quality available research evidence on the effects of CCTV on crime in public spaces. They examined the results of studies from the United Kingdom and North America that included follow-up periods of between 3 to 24 months for city centres or public housing (averaging less than 12 months), 12 to 32 months for public transport (averaging less than 24 months), and 8 to 30 months for car parks (averaging slightly more than 12 months). They concluded:

CCTV had a significant desirable effect on crime, with an overall reduction in crime of 21 per cent in experimental compared to control areas. CCTV was most effective in reducing crime in car parks, most effective when combined with improved street lighting and targeted at vehicle crimes, and more effective in reducing crime in the U.K. than in North America. (p. 21) 
However, while this example was presented as an evidence-based crime prevention analysis, there was limited information in the report on the different factors potentially affecting the results of each study in the meta-analysis.

The evaluation studies on situational prevention strategies are less clear on the long-term and lasting effects of these types of measures. The reason for this is that it is both difficult and costly to sustain these techniques for extended periods of time. As well, it is equally a challenge to assess the impact of these strategies on the overall rates of crime and to take shifts in crime patterns into account. The success of situational crime prevention strategies has made them very popular with law enforcement agencies and the general public, despite the fact that these strategies do not deal with the perceived root causes of crime. By themselves, these approaches have limited long-term value; however, when included in broader and more comprehensive approaches, they can play a key role in reducing some specific types of crime and victimization.

\section{Developmental Crime Prevention}

Crime prevention from a developmental perspective is largely based on the idea that criminal activity is determined by behavioural and attitudinal patterns that have been learned during a child's psychosocial development. Ideas concerning crime prevention and the fundamental causes of crime are really concomitant ideas. The point is that while some criminal activities are influenced by proximate events, others are influenced by key risk factors that require long-term intervention.

Research such as that done by Tremblay and Craig (1995) confirms that intervention with young children and their parents has positive effects on three key risk factors: (a) poor parenting (parents); (b) cognitive deficits (life environment); and (c) socially disruptive behaviour (school). This does not negate the importance of other structural risk factors such as poverty and a poor living environment but it does provide easier and more focused opportunities for preventive intervention. In addition, Tremblay and Craig's review of the literature indicates the positive effects of intervention on inadequate parenting. They looked at the formation of attitudes toward parenting, mother satisfaction, family communications, father participation, child abuse and neglect, as well as the rate of a return to work and further pregnancy rates. They found that to the extent that positive effects can be maintained over long periods, they are likely to have a significant effect on a child's development.

Cognitive deficits of all kinds are associated with criminal behaviour. Longitudinal studies such as those done by Moffitt (1990, as cited in Tremblay \& Craig, 1995), Farrington (1991, as cited in Tremblay \& Craig, 1995), and Stattin and KlackenbergLarsson (1991) have shown that preschoolers and elementary school children's cognitive deficits predict later criminal behaviour. Most of the studies highlighted by Tremblay and Craig (1995) confirm that interventions (such as daycare participation, special learning 
opportunities, or social skills training), which focus on stimulating cognitive development, must begin at an early age in order to have a significant impact.

Studies such as Earls (1986, as cited in Tremblay \& Craig, 1995) and Mrazek and Haggerty (1994, as cited in Tremblay \& Craig, 1995) report positive effects of early treatment on the disruptive social behaviour of children, particularly in the short term. While experience with respect to long-term effects is more limited, there are indications that short-term studies have demonstrated long-term effects (Farrington \& Tonry, 1995). Howell (1997, as cited in Lab, 2004) suggests that protective factors are individual or environmental factors that tend to increase resistance to, or inhibit the development of, problematic behaviours. However, as indicated by Catalano, Arthur, Hawkins, Berglund, and Olson (1998, as cited in Lab, 2004), children exposed to multiple risk factors are at substantially greater risk of future delinquent behaviour, even with the positive influence of some protective factors.

A good illustration of the positive influence of protective factors can be found in programs using the Healthy Families model. An evaluation of this model is provided by Boyes and Hornick (2005), who note that the model is based on the Healthy Families America Program. This model was tested in various sites across Canada, including three experimental sites of the Success by Six Healthy Families Program in Edmonton, Alberta (Norwood Child and Family Resource Centre, the Bent Arrow Traditional Healing Society, and Terra Association); the Kwanlin Dun First Nation Healthy Families Program in Whitehorse, Yukon; and the Best Start Healthy Families Program in Charlottetown, Prince Edward Island. The Healthy Families model was successfully implemented at all five sites. At all program sites, over $70 \%$ of program time was spent on client-focused activities.

Finally, the Tremblay and Craig (1995) examination of some 49 prevention experiments suggests that early childhood intervention can have a positive effect on the three very important risk factors for juvenile delinquency: disruptive behaviour, poor cognitive skills, and poor parenting. Two of these - disruptive behaviour and poor cognitive skills - also impact school performance. Furthermore, their review indicates that experiments with long-term follow-up targeting at least two of these risk factors, i.e., disruptive behaviour and poor parenting skills in childhood, have been shown to have a significant effect on decreasing future criminal behaviour. Tremblay and Craig (1995) indicate that many of the experiments that have been reviewed in the past have been small-scale confirmatory or replication type studies. Moreover, as indicated by Lab (2004):

...recent studies based on better theoretical models with quality longitudinal data have demonstrated considerable success at addressing and improving a number of important protective factors and reducing risk factors, including antisocial behaviors such as crime (see Howell, 1997; Kury and ObergfellFunchs, 2003; Loebner and Farrington, 1998). (p. 145) 
From a policy perspective, proponents of this approach believe that money invested in early prevention efforts with at-risk families will have greater payoffs than money invested later, after the child has engaged in criminal activity. However, developmental crime prevention does not sufficiently deal with certain types of crime, such as familyrelated violence, personal crimes, and white-collar or economic crime. In addition, Rosenbaum, Lurigio, and Davis (1998) note that as a society, we need to understand that children face different risk factors at different points in their development, thus dictating the need for different interventions as they develop. This is a challenge that developmental theorists have only partially dealt with since they focus principally on children and do not typically address the problems faced by youth who develop delinquent characteristics during their preadolescent or adolescent periods. These young people represent a significant portion of those exhibiting delinquent and subsequent criminal behaviour in society.

\section{Crime Prevention through Social Development}

Crime Prevention through Social Development (CPSD), or social crime prevention as it is called in Europe and in some circles in the United States, rests on what Lab (1997) refers to as the assumption that true change in crime and fear can be achieved only through attacking and altering larger social and economic problems and issues. Lab further states that advocates of such social prevention point to problems of structural inequality, poor education, economic or social powerlessness, and other related concerns. Currie (1988) suggests that the approach we need toward crime in the coming decades might be called "social environmental" or, to resurrect an old term, "human ecological". By this, Currie means a strategy that includes interventions on the level of individuals and families "at risk". It also moves beyond this level to interventions aimed at the larger social forces that have an impact at the community level and thereby put large numbers of individuals and families at risk.

Are the concepts of social prevention and Crime Prevention through Social Development synonymous? Lab (1997) suggests that from a social prevention orientation, society needs to address problems at the "macro level". The social prevention model focuses on developing programs and policies on the national scale to improve health, family life, education, housing, work opportunities, and neighbourhood activities. In addition, we can deduce that for Lab (1997), social prevention is at the frontier or the boundary of what is traditionally viewed as primary and secondary prevention.

On the other hand, social development (which is a term more in use in Canada) attempts to build upon what we believe and know about the social and economic factors that are most closely related to criminal behaviour. The National Crime Prevention Centre (2000a) presents Crime Prevention through Social Development (CPSD) as an approach to the prevention of crime and victimization, which recognizes the complex social, economic, and cultural processes that contribute to crime and victimization. CPSD seeks to strengthen the bridge between criminal justice policies and programs and the safe, secure, and pro-social development of individuals, families, and communities. 
Furthermore, the National Crime Prevention Centre (NCPC) suggests that CPSD tends to concentrate on secondary prevention measures. Such a definition implies that we should focus on key risk factors that contribute to involvement with crime such as those suggested by Crawford (1998) as well as other risk factors discussed above. Once again, these include: individual personality and behavioural factors, family influences, living conditions, school influences, peer group pressures, and recreational and employment opportunities.

One of the key characteristics of the Canadian experience with CPSD is that it is implemented on a relatively small scale and is community driven. In addition, as pointed out by the NCPC (2000a), most of the social development strategies in Canadian communities can be classified under one of three general rubrics:

1. Individual-level strategies that focus on addressing existing deficits that may place individuals at risk of involvement in crime;

2. Family-oriented strategies that seek to strengthen family capacity, such parenting programs; and

3. Community-level strategies that seek to strengthen local capacity to prevent crime.

Presumably all these strategies focus on high-risk situations.

Some of the critics of a social development approach highlight the fact that its definition and scope are quite broad. For example, Crawford (1998) suggests caution regarding social development approaches because of the potential danger in becoming either too diffused or too dominating within social policy. Social development approaches require a significant amount of human and financial resources from both within and outside the community. It is also difficult to target those responsible for, or at risk of becoming involved in, white-collar crime and so-called "victimless crimes" such as electronic commercial fraud and Internet crime. In addition, the issue of violence against women, especially within private spaces, is not readily amenable to social development intervention strategies. Finally, it is difficult to assess the impact of these broad prevention strategies both in the short and long term since many variables can have a potential impact on outcomes.

\section{Conclusion: Toward a Comprehensive Crime Prevention Strategy}

I have noted key arguments that suggest the need for a new and different crime prevention approach. Crime and victimization continue to exist and while official data indicate a reduction in overall levels of crime, reasonably unchanged levels of victimization counterbalance this. Second, the public view is that the agents of the criminal justice system (police, courts, and correctional services) have not been able to demonstrate that they can reduce or control crime and victimization. In addition, many believe that the criminal justice system contributes to the increase in crime through its use of prisons, which can become training grounds for criminals. The current situation begs 
the question as to what types of crime prevention strategies are most appropriate and able to produce effective results.

It is my belief that a meaningful strategy for preventing crime should be based on a social development approach that strengthens individuals, families, and communities. Such an approach should be designed and managed at the local level. The strength of a community-based social development approach is that it can address specific factors that are strongly associated with youth as well as adult criminal activity. These include violence in the home, unsupportive family life and parental behaviour, poverty, poor housing, failure in school and illiteracy, drug and alcohol abuse, and unemployment. Advocates of social crime prevention approaches highlight existing and entrenched societal problems of structural inequality, poor education, unemployment, poor employment options, economic and social powerlessness, and other related concerns. These social inequities disadvantage many in Canadian society and have a particular impact on children and youth, the elderly, and single parents.

Prevention based on social development makes sense for our communities by making them safer and more attractive places for all citizens. Moreover, there is ample evidence that well-designed social development programs prevent crime and are costeffective. The NCPC (2000a), for example, points to American evaluations that show that Crime Prevention through Social Development pays handsome dividends. The Perry Preschool Project in Michigan has been shown to be responsible for significantly reducing juvenile and adult crime in the long term. This conclusion is based on almost 30 years of participant follow-up.

Social development strategies do not, however, necessarily alleviate the short- or medium-term needs of communities that are in crisis and seeking an immediate reduction in crime. As indicated by the Aspen Institute (2002, as cited in Hunsley, 2003):

Comprehensive community initiatives have made great strides in identifying the many moving parts that have to come together to achieve change and in understanding how difficult it is to implement complex community change strategies and to acquire the capacity and resources needed to make them work effectively. (p. 7)

To achieve this, we must add supplementary prevention strategies, usually situational in nature and often including community capacity building, to the longer-term social development approach. Their aim must be to generate a greater sense of safety and well-being, as well as increasing socio-economic benefits for those residents most in need.

A comprehensive crime prevention strategy needs to meet several important requirements to be effective. These include building active partnerships throughout the community, ensuring that the roles and responsibilities of all players - and especially the police - are clearly defined, putting in place a sound governance structure to help in 
decision-making, and implementing intervention strategies using an evidence-based approach.

Comprehensiveness thus refers to a systematic process of identifying the priority concerns of a given community, using diagnostic tools to identify and target relevant risk and protective factors particularly with respect to children and youth across multiple domains, and identifying and implementing evidence-based responses that match the prioritised factors. (Hawkins, Catalano, \& Arthur, 2002, pp. 955-956)

A comprehensive strategy should be designed to address the multiple risk and protective factors associated with crime and victimization at the individual, family, community, and societal level. Such an approach should yield a higher return than discrete approaches. Establishing a comprehensive community-wide approach is a longterm effort, however, and it may not be a practical option if, for example, key community agencies are unwilling or unable to respond to some specific problems or issues. In such cases, alternative methods are available to provide support for communities facing significant problems that possess limited resources or consensus on how to deal with these problems.

Wyrick and Howell (2004) highlight one of these methods. Their strategic riskbased response model was applied to youth gangs, although in my view it is equally applicable to broader community concerns. They state:

Comprehensive community approaches still remain the ideal communitylevel response to youth gangs. Many communities, however, cannot implement comprehensive programs for a variety of legitimate reasons and these communities can benefit from developing a strategic risk-based response to youth gangs. (p. 20)

I believe their approach can provide a framework for intervention when key community agencies are unwilling or unable to respond to all the particular concerns identified in a community assessment process. The goal then becomes to focus on key or core issues, such as children and youth at risk, and on factors where there is the most potential for joint partnership intervention.

One key lesson learned by the National Strategy for Community Safety and Crime Prevention (NSCSCP) and reported by Léonard, Rosario, Scott, and Bressan (2005) suggests the need to ensure that the roles and responsibilities of local advisory groups, project coordinators, and partnering organizations (or what I referred to earlier as governance structures) are clearly articulated. Another lesson from this study focuses on the importance of building and maintaining local partnerships as key to sustaining collaborative action. To this, I would add the importance of ensuring the full participation of the police in any comprehensive local crime prevention strategy. Police officers see themselves as peace officers whose primary responsibility is to enforce the law and maintain public order. As Caputo and Vallée (2010) point out: 
A new integrated and comprehensive service delivery model could be a way of giving police officers an expanded role in community problem solving. Such a model would emphasize their skills and expertise as peace officers and law enforcers. It would be build on their operational expertise and experience as first responders. (p. 93)

Finally, it is important that any intervention be reviewed on an ongoing basis to ensure that it is on track and meeting its objectives. According to Welsh and Farrington (2005), "Systematic reviews are the most comprehensive method to assess the effectiveness of crime prevention measures" (p. 349). They also point out that, "in an evidence-based society, [systematic reviews] would be the source that governments would turn to for help in the development of policy” (p. 348). This view is certainly supported by those assessing the lessons learned through the NSCSCP. I share the view that evaluation is a vital element of success in the development, implementation, and sustainability of effective crime prevention programs. 


\section{References}

Arcand, M. A., \& Cullen, J. E. (2004). Promising practices: Survey of police involvement in crime prevention through social development in Canada. Ottawa: Public Safety and Emergency Preparedness Canada.

Aspen Institute. (2002). Voices from the field II: Reflections on comprehensive community change. In T. Hunsley (2003, November), Presentation to the ICPC

international symposium on crime prevention, Pretoria, South Africa.

Bennett, T. (1990). Evaluating Neighbourhood Watch. Aldershot, UK: Gower.

Boyes, M., \& Hornick, J. (2005). An evaluation of the healthy families model in five Canadian communities. A report undertaken on behalf of the National Crime Prevention Centre. Ottawa: Public Safety and Emergency Preparedness Canada.

Caputo, T., \& Vallée, M. (2010). Creating safer communities for children and youth: The role of the police in crime prevention. International Journal of Child, Youth and Family Studies, 1(1), 78-96.

Clarke, R. V. (1983). Situational crime prevention: Its theoretical basis and practical scope. In M. Tonry \& N. Morris (Eds.), Crime and justice (Vol. 4, pp. 225-256). Chicago: University of Chicago Press.

Corrado, R. R., Cohen, I. M., \& Davies, G. (2005). Social capital and community crime prevention programs: Impacting research. Unpublished paper prepared for the Policy Research Initiative, Ottawa.

Crawford, A. (1998). Crime prevention and community safety: Politics, policies and practices. London: Longman Criminology Series.

Crowe, T. D. (2000). Crime prevention through environmental design: Applications of architectural design and space management concepts (2nd ed.). Woburn MA: National Crime Prevention Institute.

Currie, E. (1988). Two visions of community crime prevention. In T. Hope \& M. Shaw (Eds.), Communities and crime reduction (pp. 280-286). London: Her Majesty's Stationery Office.

DesChamps, S., Brantingham, P. L., \& Brantingham, P. J. (1991). The British Columbia transit fare evasion audit: A description of a situational prevention process. Security Journal, 2, 211-218.

Earnscliffe Research and Communications. (2000, April). Canadian public survey. Ottawa: Author. 
Ekblom, P. (1992). Preventing post office robberies in London: Effects and side effects. In R. V. Clarke (Ed.), Situational crime prevention: Successful case studies (pp. 6674). New York: Harrow and Heston.

EKOS Research Associates Inc. (2001). Survey of Canadian attitudes toward the prevention of crime. Ottawa: Author.

EKOS Research Associates Inc. (2004, March 26). Canadian attitudes toward crime prevention: Final integrated report. Ottawa: Justice Canada.

Gendreau, P., \& Ross, R. (1987). Revivication of rehabilitation: Evidence from the 1980s. Justice Quarterly, 4(3), 349-407.

Gerbner, G., Cirel, P., Evans, D., McGillis, D., \& Whitcomb, D. (1977). Community crime prevention program, Seattle Washington: An exemplary project. Washington, DC: National Institute of Justice.

Government of Canada. (1993). Report of the Standing Committee on Justice and the Solicitor General. Ottawa: House of Commons.

Hawkins, J. D., Catalano, R. F., \& Arthur, M. W. (2002). Promoting science-based prevention in communities. Addictive Behaviors, 27(6), 951-976.

Harvey, L., Grimshaw, P., \& Pease, K. (1989). Crime prevention delivery: The work of crime prevention officers. In R. Morgan \& D. J. Smith (Eds.), Coming to terms with policing (pp. 323-339). London: Routledge.

Hastings, R. (1995). Crime prevention and criminal justice. In T. O’Reilly Fleming (Ed.), Post-critical criminology (pp. 315-328). Toronto: Prentice-Hall.

Jacobs, J. (1961). The death and life of great American cities. New York: Vintage.

Jamieson, Beals, Lalonde \& Associates. (2000). Crime prevention practice in Canada. Ottawa: Justice Canada.

Jamieson, W., \& Hart, L. (2003). Compendium of promising crime prevention practices. Ottawa: The Caledon Institute of Social Policy.

Lab, S. P. (1997). Crime prevention: Approaches, practices and evaluations (3rd ed.). Cincinnati, OH: Anderson Publications.

Lab, S. P. (2004). Crime prevention: Approaches, practices and evaluations (5th ed.). Cincinnati, OH: Anderson Publications. 
Lejins, P. P. (1967). The field of prevention. In W. E. Amos \& C. E. Wellford (Eds.), Delinquency prevention: Theory and practices (pp. 1-21). Englewood Cliffs, NJ: Prentice Hall.

Léonard, L., Rosario, G., Scott, C., \& Bressan, J. (2005). Building safer communities: Lessons learned from Canada's national strategy. Canadian Journal of Criminology and Criminal Justice, 47(2), 233-250.

National Crime Prevention Centre. (2000a). Crime prevention through social development. Ottawa: Justice Canada.

National Crime Prevention Centre. (2000b). Situational crime prevention. Ottawa: Justice Canada.

Newman, O. (1972). Defensible space: Crime prevention through urban design. New York: Macmillan.

Rosenbaum, D. P. (Ed.). (1986). Community crime prevention: Does it work? Beverley Hills, CA: Sage.

Rosenbaum, D. P., Lurigio, A. J., \& Davis, R. C. (1998). The prevention of crime: Social and situational stategies. Toronto: Wadsworth Canada.

Sampson, R. J., \& Raudenbush, S. W. (1999). Systematic social observations of public spaces: A new look at disorder in urban neighborhoods. American Journal of Sociology, 105(3), 630-651.

Stattin, H., \& Klackenberg-Larsson, I. (1991). The short- and long-term implications for parent-child relations of parents' prenatal preferences for their child's gender. Developmental Psychology, 27(1), 141-147.

Tonry, M., \& Farrington, D. P. (Eds.). (1995). Building a safer society: Strategic approaches to crime prevention. Chicago: The University of Chicago Press.

Tremblay, R., \& Craig, W. M. (1995). Developmental crime prevention. In M. Tonry \& D. P. Farrington (Eds.), Building a safer society: Strategic approaches to crime prevention (pp. 151-236). Chicago: The University of Chicago Press.

Welsh, B. C., \& Farrington, D. P. (2004). Evidence-based crime prevention: The effectiveness of CCTV. Crime Prevention and Community Safety: An International Journal, 6(2), 21-33.

Welsh, B. C., \& Farrington, D. P. (2005). Evidence-based crime prevention: Conclusions and directions for a safer society. Canadian Journal of Criminology and Criminal Justice, 47(2), 337-354. 
Wilson, J. Q. (1983). Thinking about crime (revised edition). New York: Vintage Books/Random House.

Wilson, J. Q., \& Kelling, G. (1982, March). Broken windows: The police and neighborhood safety. Atlantic Monthly, 249, 29-38.

Wilson, J. Q., \& Kelling, G. (1989, February). Making neighborhoods safe. Atlantic Monthly, 263, 46-52.

Wyrick, P. A., \& Howell, J. C. (2004). Strategic risk-based response to youth gangs. Juvenile Justice, IX(1), 20-29. 